\title{
LA ASERTIVIDAD Modelo de Comunicación en las Organizaciones
}

Lic. OLINDA EGÚSQUIZA PEREDA (*)

La humanidad ha dedicado innumerables esfuerzos para comunicarse a través de los tiempos. El hombre siempre ha mantenido una comunicación ya sea con gestos, mímicas, sonidos, gráficas, etc. Hoy en día, en un mundo globalizado y con los avances de la ciencia y la tecnología la comunicación se hace más rápida (radio, TV, teléfono, fax, internet, satélites, celulares, etc.), y esto acarrea nuevos problemas como la calidad, la eficacia, la efectividad y la asertividad en este proceso.

La comunicación es inevitable porque aun en su ausencia, comunicamos algo. Podemos dejar de realizar una serie de actividades en nuestras vidas, pero:jamás lograremos dejar de comunicarnos; aun sin palabras, nuestros silencios y actividades están "comunicando" algo.

La comunicación es la piedra angular en las organizaciones, la interacción de sus miembros con clientes, proveedores, aliados, etc. se hace cada día más necesaria; es por ello que la calidad en la comunicación adquiere cada vez más importancia. Es posible evaluar el nivel del progreso de una organización a través de la capacidad de comunicación entre sus integrantes, en esto reside el éxito o el fracaso.
La conducta asertiva, entendida como la capacidad de defender nuestros derechos respetando los ajenos, puede contribuir a que mejoremos nuestros roles como emisores y receptores y, así, realizaremos un eficiente manejo de cada elemento del circuito comunicativo. Por lo tanto, la comunicación asertiva significa tener la habilidad para transmitir y recibir los mensajes, sentimientos, creencias $\mathrm{u}$ opiniones propios o ajenos de una manera honesta, oportuna y respetuosa para lograr como meta una comunicación que nos permita obtener cuanto queremos sin lastimar a los demás. (practicar la empatía).

El nuevo líder de las organizaciones aprendientes tiene que saber comunicar asertivamente. Debe dedicar más tiempo comunicándose que haciendo cosas, del mismo modo aprenderá a comunicarse con los empleados para que trabajen en "equipo", teniendo como meta un mismo objetivo, y por consiguiente, practicar una comunicación asertiva de puertas abiertas.

El Líder-Asertivo debe practicar el empowerment, palabra de moda que creó el Gurú Empresarial Peter Block y que se traduce como "facultar o entregar poder". Este concepto no debe confundirse, en el

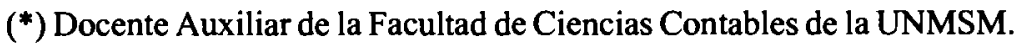


sentido de que todos los Jefes cedan el poder a sus subordinados para que puedan decidir todo, esto sería una "anarquía". Es importante que cada Jefe sepa definir fronteras, de acuerdo al nivel de competencia del subordinado, a través de las decisiones y esto es posible gracias a la comunicación asertiva; de esa forma la empresa crecerá en un mercado competitivo y globalizado.

\section{'ASERTIVIDAD}

Existen numerosas definiciones de Asertividad, es una palabra de moda que suena a novedad y que, en efecto, designa un enfoque muy moderno y dinámico.

La palabra proviene del latín asserere, asser tum (Aserción) que significa afirmar. Así pues, Asertividad significa afirmación de la propia personalidad, confianza en sí mismo, autoestima, aplomo, fe gozosa en el triunfo de lajusticia y la verdad, vitalidad pujante, comunicación segura y eficiente.

La asertividad puede ayudamos mucho a mejorar nuestra comunicación, a facilitar nuestra interrelación con las personas y a disminuir el estrés. La asertividad es una conducta que puede resumirse como un comportamiento mediante el cual defendemos nuestros legítimos derechos sin agredir ni ser agredidos.

En un principio, la asertividad fue concebida como una característica de la personalidad. En esos términos se pensó que algunas personas eran asertivas y otras no. Años más tarde, basados en la observación de que la mayoría de las personas podían ser asertivas en algunas circunstancias y poco o nada en otras, Wolpe y Lazarus, redefinieron el concepto como la expresión de los derechos y sentimientos personales.

La conducta asertiva se dirige a la defensa de los derechos propios de modo tal que no se violen los ajenos. La persona asertiva, consigue expresar sus gastos e intereses de forma espontánea, hablar de sí mismo sin vergüenza, aceptar los halagos sin incomodidad, discrepar sin miedo, abiertamente, pedir aclaraciones de las cosas y saber decir no.

\section{CARACTERISTICAS DE UNA PERSONA 'ASERTIVA}

- La persona asertiva siente una gran libertad para manifestarse, para expresar lo que es, lo que piensa, lo que siente, y quiere sin lastimar a los demás. (Es empático).

- Es capaz de comunicarse con facilidad y libertad con cualquier persona, sea ésta extraña o conocida y su comunicación se caracteriza por ser directa, abierta, franca y adecuada.

- En todas sus acciones y en manifestaciones se respeta a sí misma y acepta sus limitaciones, tiene siempre su propio valor y desarrolla su autoestima; es decir, se aprecia y se quiere a sí misma, tal como es.

- Su vida tiene un enfoque activo, pues sabe lo que quiere y trabaja para conseguirlo, haciendo lo necesario para que las cosas sucedan, en vez de esperar pasivamente a que éstos sucedan por arte de magia. Es más proactivo que activo.

- Acepta o rechaza, de su mundo emocional, a las personas: con delicadeza, pero con firmeza, establece quiénes van a ser sus amigos y quiénes no.

- Se manifiesta emocionalmente libre para expresar sus sentimientos. Evita los dos extremos: por un lado la represión y por el otro la expresión agresiva y destructiva. 


\section{Componentes no verbales de la comunicación asertiva}

La comunicación no verbal, por mucho que se quiera eludir, es inevitable en presencia de otras personas. Un individuo puede decidir no hablar, o ser incapaz de comunicarse verbalmente; pero, todavía sigue emitiendo mensajes acerca de sí mismo a través de su cara y su cuerpo. Los mensajes no verbales a menudo son también recibidos de forma medio consiente: la gente se forma opiniones de los demás a partir de su conducta no verbal, sin saber identificar exactamente qué es lo agradable o irritante de cada persona en cuestión.

Para que un mensaje se considere transmitido de forma socialmente hábil (asertiva), las señales no verbales tienen que ser congruentes con el contenido verbal.

Las personas no asertivas carecen a menudo de la habilidad para dominar los componentes verbales y no verbales apropiados de la conducta, y de aplicarlos conjuntamente, sin incongruencias. En un estudio realizado por Romano y Bellack, a la hora de evaluar una conducta asertiva, eran la postura, la expresión facial y la entonación las conductas no verbales que más altamente se relacionaban con el mensaje verbal.

Analicemos cada uno de los principales componentes no verbales que contiene todo mensaje que emitimos:

\section{La mirada}

Casi todas las interacciones de los seres humanos dependen de miradas recíprocas.

La cantidad y tipo de miradas comunican actitudes interpersonales, de tal forma que la conclusión más común que una persona extrae cuando alguien no lo mira a los ojos es que está nervioso y le falta confianza en sí mismo.

Los sujetos asertivos miran más mientras hablan que los sujetos poco asertivos. De esto depende que la utilización asertiva de la mirada, como componente no verbal de la comunicación, implique una reciprocidad equilibrada entre el emisor y el receptor, variando la fijación de la mirada según se este hablando (40\%) o escuchando $(75 \%)$.

\section{La expresión facial}

La expresión facial.juega varios papeles en la interacción social humana:

- Muestra el estado emocional de una persona, aunque ésta pueda tratar de ocultarlo.

- Proporciona una información continua sobre si está comprendiendo el mensaje, si está sorprendido, de acuerdo, en contra, etc., en relación con lo que se está diciendo.

- Indica actitudes hacia las otras personas.

La persona asertiva adoptará una expresión facial que esté de acuerdo con el mensaje que quiere transmitir. Es decir, no adoptará una expresión facial que sea contradictoria o no se adapte a lo que se quiere decir. La persona no asertiva, por ejemplo, frecuentemente está "cociendo" por dentro cuando se le da una orden injusta; pero su expresión facial muestra amabilidad.

\section{La postura corporal}

Existen cuatro tipos de posturas:

Postura de acercamiento: indica atención, que puede interpretarse de 
manera positiva (simpatía) o negativa (invasión) hacia el receptor.

Postura de retirada: suele interpretarse como rechazo, repulsa o frialdad.

Postura erecta: indica seguridad, firmeza, pero también puede reflejar orgullo, arrogancia o desprecio.

Postura contraída: suele interpretarse como depresión, timidez y abatimiento físico o psíquico.

\section{La persona asertiva adoptará generalmente una postura cercana $y$ erecta, mirando de frente a la otra persona.}

\section{Los gestos}

Los gestos son básicamente culturales. Las manos y, en un grado menor, la cabeza y los pies, pueden producir una amplia variedad de gestos que se usan bien para amplificar y apoyar la actividad verbal o bien para contradecirla tratando de ocultar los verdaderos sentimientos.

Los gestos asertivos son movimientos desinhibidos. Sugieren franqueza, seguridad en uno mismo y espontaneidad por parte del que habla.

\section{Componentes paralingülsticos}

El área paralingüístico o vocal, hace referencia a "cómo" se transmite el mensaje; mientras que el área propiamente lingüistica o habla, estudia "lo que" se dice. Las señales vocales paralingüisticas incluyen:

Volumen: en una conversación asertiva, éste tiene que estar en consonancia con el mensaje que se quiere transmitir.
Tono: el tono asertivo debe de ser uniforme y bien modulado, sin intimidar a la otra persona; pero, basándose en una seguridad.

Fluidez-Perturbaciones del habla: excesivas vacilaciones, repeticiones. etc., pueden causar una impresión de inseguridad, inapetencia o ansiedad, dependiendo de cómo lo interprete el interlocutor. Estas perturbaciones pueden estar presentes en una conversación asertiva siempre y cuando estén dentro de los limites normales y estén apoyados por otros componentes paralingüistícos apropiados.

Claridad y velocidad: el emisor de un mensaje asertivo debe hablar con una claridad tal que el receptor pueda comprender el mensaje sin tener que reinterpretar o recurrir a otras señales alternativas. La velocidad no debe ser muy lenta ni muy rápida en un contexto comunicativo normal, ya que ambas anomalías pueden distorsionar la comunicación.

\section{COMPONENTES VERBALES DE LA COMUNICACIÓN.ASERTIVA}

La conversación es el instrumento verbal por excelencia de la que nos servimos para transmitir información y mantener más relaciones sociales adecuadas. Implica un grado de integración compleja entre las señales verbales y las no verbales, tanto emitidas como recibidas. Elementos importantes de toda conversación son:

Duración del habla: la duración del habla está directamente relacionada con la asertividad, la capacidad de enfrentarse a situaciones y el nivel de ansiedad social. En líneas generales, a mayor duración del habla más asertiva 
se puede considerar a la persona; pero, en ocasiones, el habla durante mucho rato puede ser un indicativo de una excesiva ansiedad.

Retroalimentación (feed back): cuando alguien está hablando necesita saber si los que lo escuchan lo comprenden, le creen, están sorprendidos, aburridos, etc.

Una retroalimentación asertiva consistirá en un intercambio mutuo de señales de atención y comprensión dependiendo, claro está, del tema de conversación y de los propósitos del mismo.

Preguntas: son esenciales para mantener la conversación, obtener información y mostrar interés por lo que dice la otra persona. El no utilizar preguntas puede provocar cortes en la conversación y la sensación de desinterés.

\section{Principales causas de la falta de asertividad}

A. LA PERSONA NO HA APRENDIDO A SER ASERTIVA O LO HA APRENDIDO DE FORMA INADECUADA

No existe una "personalidad innata" asertiva o no asertiva, ni se heredan caracteristicas de asertividad. La conducta asertiva se va aprendiendo por imitación y refuerzo, es decir, por lo que nos han transmitido como modelos de comportamiento y como dispensadores de premios y castigos nuestros padres, maestros, amigos, medios de comunicación, etc.

En la historia de aprendizaje de la persona no asertiva pueden haber ocurrido las siguientes cosas:

- Castigo sistemático a las conductas asertivas: entendiendo por castigo no necesariamente el físico; sino, todo tipo de recriminaciones, desprecios o prohibiciones.

- Falta de refuerza suficiente a las conductas asertivas: puede ocurrir que la conducta asertiva no haya sido sistemáticamente castigada, pero tampoco suficientemente reforzada. La persona, en este caso, no ha aprendido a valorar este tipo de conducta como algo positivo.

- La persona no ha aprendido a valorar el refuerzo social: si a una persona le son indiferentes las sonrisas, alabanzas, simpatias y muestras de cariño de los demás, entonces no esgrimirá ninguna conducta que vaya encaminada a obtenerlos.

- La persona obtiene más refuerzo por conductas no asertivas o agresivas: es el caso de la persona tímida, indefensa, a la que siempre hay que estar ayudando o apoyando. El refuerzo que obtiene (la atención) es muy poderoso. En el caso de la persona agresiva, a veces, el refuerzo (por ejemplo, "ganar" en una discusión o conseguir lo que quiere) llega más rápidamente, a corto plazo, si se es agresivo que si se intenta ser asertivo.

- La persona no sabe discriminar adecuadamente las situaciones en las que debe emitir una respuesta concreta: la persona a la que los demás consideran "plasta, pesado", está en este caso. Esta persona no sabe ver cuándo su presencia es aceptada y cuándo no, o en qué casos se puede insistir mucho en un tema y en cuáles no. También está en este caso la persona "patosa" socialmente que, por ejemplo, se ríe cuando hay que estar serio o hace un chiste inadecuado. 


\section{B. LA PERSONA CONOCE LA CON- DUCTA APROPIADA, PERO SIENTE TANTA ANSIEDAD QUE LA EMITE DE FORMA PARCIAL}

En este caso, la persona con problemas de asertividad ha tenido experiencias altamente aversivas (de hecho o por lo que ha interpretado) que han quedado unidas a situaciones concretas.

\section{LA PERSONA NO CONOCE O RECHAZA SUS DERECHOS}

¿Qué son los derechos Asertivos? Son unos derechos no escritos que todos poseemos, pero que muchas veces olvidamos a costa de nuestra autoestima. No sirven para "pisar" al otro, pero sí para considerarnos a la misma altura que todos los demás.

\section{TABLA DE LOS DERECHOS ASERTIVOS}

1. El derecho a ser tratado con respeto.

2. El derecho a tener y expresar los propios sentimientos y opiniones.

3. El derecho a ser escuchado y tomando en serio.

4. El derecho a juzgar mis necesidades, establecer mis prioridades y tomar mis propias decisiones.

5. El derecho a decir "NO" sin sentir culpa.

6. El derecho a pedir lo que quiero, dándome cuenta que también mi interlocutor tiene derecho a decir "NO".

7. Derecho a cambiar.

8. El derecho a cometer errores.

9. El derecho a pedir información y ser informado.

10. El derecho a obtener aquello por lo que pagué.

11. El derecho a decidir no ser asertivo.

12. El derecho a ser independiente.

13. El derecho a decidir qué hacer con mis propiedades, cuerpo, tiempo, etc., mientras no se violen los derechos de otras personas.

14. El derecho a tener éxito.
15. El derecho a gozar y disfrutar.

16. El derecho a mi descanso, aislamiento, siendo asertivo.

17. El derecho a superarme, aun superando a los demás.

\section{LA PERSONA POSEE UNOS PATRONES IRRACIONALESDE PENSAMIENTOQUE LE IMPIDEN ACTUAR DE FORMA ASERTIVA}

Las "creencias" o esquemas mentales son parte de una lista de "ideas irracionales" que Albert Ellis ideó hace ya unos años.

Se supone que todos tenemos, desde pequeños, una serie de «convicciones o creencias». Éstas están tan arraigadas dentro de nosotros que no hace falta que, en cada situación, nos volvamos a plantear para decidir cómo actuar o pensar. Es más, suelen salir en forma de "pensamiento automático", tan rápidamente que, a no ser que hagamos un esfuerzo consciente por retenerlos, casi no nos daremos cuenta de que nos hemos dicho eso.

Albert Ellis, psicólogo de los años 50, delimitó 10 de estas convicciones, que todos poseemos en mayor o menor medida.

Ellis las llamó «irracionales» ya que, según él, no responden a una lógica no son objetivas. En efecto, tomadas al pie de la letra nadie realmente "necesita" ser amado para sobrevivir, ni "necesita" ser competente para tener la autoestima alta.

\section{Tipología de los individuos con problemas de asertividad}

Las personas con escollos de asertividad pueden clasificarse en cinco tipos básicos:

\section{El indeciso}

Permite que lo desplacen, no sabe 
cuándo ni cómo defenderse y permanece pasivo ante cualquier situación; si alguien le pega contestará: "disculpe".

Para evitar todo fatalismo afirmamos que no importa cuán grande puede ser el problema de indecisión, siempre hay un punto en el cual basarse para empezar un cambio efectivo de la personalidad.

\section{El individuo con escollos en la comunicación}

En la comunicación asertiva podemos distinguir cuatro aspectos de conducta:

- Ser abiertos

- Ser directos

- Ser sinceros

- Ser adecuados al "aquí y ahora"

De esto se deducen 4 tipos de escollos a la asertividad:

\section{Comunicación cerrada}

Es el diálogo de sordos.

\section{Comunicación indirecta}

Se caracteriza por la locuacidad, superficialidad de sentimientos, falta de deseos claros, reticencias y conflictos nebulosos en lo que se refiere a relaciones íntimas.

\section{Comunicación no sincera o seudoasertiva}

Esta comunicación se caracteriza porque el individuo parece abierto, franco, generalmente apropiado y con frecuencia extrovertida; pero, esta asertividad aparente esconde una ausencia de sinceridad. El tipo de personas que se manifiestan de esta manera tienen conflictos con la intimidad y padecen una ausencia crónica de satisfacción en la vida.

\section{Comunicación inapropiada}

La persona que tiene una comunicación inapropiada expresa lo que piensa que es correcto, pero lo hace en un momento inoportuno. Un ejemplo es la esposa que, cuando el marido le dice: "Tenemos una fiesta mañana en la noche en casa de los Ramírez", le contesta: "No tengo qué ponerme".

Tal insensibilidad hacia los demás conduce frecuentemente a una conducta centrada en uno mismo y una falta de consideración del prójimo.

\section{La persona que sufre una "grieta asertiva"}

Algunas personas pueden fallar en una o dos áreas de asertividad y tener éxito en otras.

Existen individuos capaces de expresar abiertamente sus sentimientos de ternura y que no pueden mostrar otro tipo de sentimientos y viceversa.

Asimismo, un hombre puede ser muy pasivo en la oficina y ser un tirano en su casa. O puede actuar asertivamente en el trabajo, en sus relaciones sociales y con sus hijos, y no ser, a pesar de ello, asertivo con su esposa.

\section{El individuo con insuficiencias de conducta}

Existen personas a quienes se les dificulta algunas conductas específicas, como mantener contacto con los ojos, comenzar a sostener una plática con personas del otro sexo, o manejar una confrontación. Estas habilidades pueden aprenderse a través de prácticas asertivas.

\section{La persona con bloqueos específicos}

Esta persona sabe lo que debería hacer y posee la habilidad suficiente para realizarlo, pero el miedo que tiene al rechazo, enojo, escrutinio, evaluación crítica, intimidad o 
hacer el ridículo la inhiben para llevar a cabo acciones tales como la expresión de la ternura o los intentos de ser creativo en un asunto determinado.

Si queremos ir más a fondo, podemos encontrar un común denominador, o si se quiere, una raíz común para todos los sujetos con problemas de asertividad. Este tronco común es el complejo de inferioridad.

Mencionaremos a continuación algunas de las caretas y máscaras que suele tomar este complejo:

- Querer tener siempre la razón

- Enojarse con suma facilidad

- Necesidad obsesiva de "ser más" que los otros, de "valer más", de controlar dictatoriamente las situaciones

- Dificultad y resistencia para aceptar los propios errores

- Intolerancia a los desacuerdos

\section{LA ASERTIVIDAD, ELEMENTO DINÁMICO DE LA EMPR'ESA}

Existen dos áreas básicas en la vida de un individuo: la familia y el trabajo. La forma de enfrentarse a ellas también revela su grado de asertividad.

Para ser asertivo en cualquiera de las dos áreas hay que poseer una orientación activa y fijarse metas que consoliden el autoestima.

En la relación íntima con la familia y en el amor el propósito debe ser la franqueza, la comunicación y el compartir todo el ser emocional de uno. Los sentimientos vienen primero.

En el trabajo, el énfasis asertivo es exactamente a la inversa. La actuación viene primero, los sentimientos después. El propósito consiste en la productividad y el logro. Debido a esto, las relaciones con los demás en el trabajo tienden a ser más superficiales que íntimas. En los sentimientos que expresa el individuo se dan mayor énfasis a la adaptación que a la franqueza.

El trabajo se convierte en extensión ' 3 uno mismo y en expresión de sí. A esto se añade el estilo, el ritmo, la velocidad, el modo peculiar de enfrentarse a los problemas.

Cuando más asertivo sea alguien en relación con el trabajo y más dispuesto se halle a afirmar con su actuación "este soy yo", mayores satisfacciones obtendrá.

\section{a. Cinco artes básicas de la aserción en el trabajo}

\section{- Orientación activa}

Refleja el hábito de meditar bien las metas de trabajo, los pasos que se han de dar para conseguirlas y cómo utilizar al máximo el talento al llevarlas a cabo.

\section{- Capacidad para hacer el trabajo}

Es importante, en primer lugar, dominar las artes necesarias para ese empleo en particular. Pero también es primordial tener dominio propio, poseer buenos hábitos de trabajo, disciplina y concentración.

\section{- Control de las ansiedades y temores}

Las reacciones emocionales inadecuadas interfieren en la realización del trabajo. La tensión general puede producir fatiga, irritabilidad y juicios erróneos. El temor a una situación específica de trabajo puede llevar a evitar las tareas necesarias para que se realice el trabajo e impedir al sujeto conseguir sus metas en el empleo.

- Buenas relaciones Interpersonales

Un experimentado consejero de personal comenta: "La mayoría de los 
despidos obedecen a que algunos no saben llevarse bien con los demás". Hay que ser capaz de relacionarse con los iguales, subordinados y superiores; saber presentar solicitudes y demandas, saber pedir favores sin rebajarse y sin molestar, decir "no" cuando es necesario y rechazar los desaires con dignidad.

\section{- El arte de negociar}

Este arte requiere un conocimiento de la sociedad laboral y las artes específicas que le permitirán al sujeto trabajar dentro, a través de o contra la misma, con el fin de conseguir sus metas particulares, respetando a los otros.

\section{b. Seis categorías de personas carentes de aserción en el trabajo}

\section{- El encasillado}

Sabe realizar su trabajo, todos lo aprecian y respetan, pero no llega a ninguna parte. No lo promueven, tiene pocos aumentos de sueldo; más trabajo sí, pero no más responsabilidad ni grandes emolumentos.

Desea avanzar, de vez en cuando expresa sus deseos; pero lo hace de modo tan tentativo que el mensaje no llega a su destino, o es fácilmente ignorado. Y aparece siempre en el mismo lugar porque a la compañía le conviene, pero no a él.

\section{- El que pasa inadvertido}

Realiza un trabajo excelente, pero nadie se da cuenta. Otros se atribuyen el mérito de sus actos. El problema radica en que tiene el potencial y la ambición necesaria para progresar; pero, como es inseguro, no sabe llamar la atención hacia sus propios logros.

Su jefe y sus compañeros de trabajo se aprovechan de su cerebro, pero él lo permite... y se traga el disgusto de ser así y ser tratado así.

\section{- EI "difícil"}

Confunde la aserción con la agresión. Su trabajo es bueno, pero es desorganizado en la oficina y en la fábrica. Provoca disgustos y se muestra en desacuerdo con todo el mundo. Aunque sus ideas son excelentes, sus modales desagradables y hostiles molestan a los demás, tanto que ni siquiera escuchan lo que se les dice.

\section{- El indisciplinado}

Tal vez se demora, o llega tarde al trabajo, o se pasa el día soñando. Cuando al fin se lanza su labor es correcta; pero, los hábitos deficientes de trabajo le impiden promoción. Los que reconocen su talento se preguntan por qué no ha triunfado. En cierto momento sus superiores se sintieron desilusionados, luego dejaron de esperar una gran actuación, y con frecuencia les irritó el hecho de que su falta de disciplina les creara algunos problemas. Teme que lo despidan... y de hecho se ve despedido con frecuencia.

\section{-EI quejoso}

Su problema es la pasividad. Se queja constantemente de las exigencias del trabajo, del ambiente de la oficina, del modo en que los demás hablan o actúan con respecto a él. Pero nunca piensa en lo que puede hacer al respecto. Cree que «ellos deberían hacer algo». Pero no discute la situación en serio, ni hace sugerencias a las personas adecuadas. Se queja y gruñe en situaciones y lugares en donde sus murmullos no pueden llevar a un cambio.

\section{- El explotado}

Dice que sí a toda petición. No sólo está sobrecargado de trabajo sino que con frecuencia cede su tiempo libre y pocas veces recibe siquiera un "gracias" por sus esfuerzos. 
La decisión del tipo de trabajo que quiere conseguir y mantener, y el modo en que quiere comportarse y actuar en el empleo es algo que sólo depende de usted. No tomar esa decisión lleva a consecuencias desafortunadas tales como la frustración, el aburrimiento o la infelicidad. La vocación es un área importante en la vida, por eso estas situaciones afectan a todas las demás áreas de la existencia.

\section{CONCLUSIONES}

1. La asertividad se refiere a defender los derechos propios expresando lo que se cree, piensa y siente de manera directa, clara en un momento oportuno y respetando los derechos de los demás.

2. La comunicación asertiva, considerada elemento dinámico de la empresa, debe ser tomada muy en cuenta por los gerentes ya que va a ayudar mucho en el manejo de sus empleados y en todas sus negociaciones.

3. El nuevo Lider-Mentor de las Organizaciones Aprendientes, mediante una comunicación asertiva, puede lograr que su personal siempre se mantenga motivado y realice el trabajo en equipo. La interrelación entre el empleado y el empleador va a depender de la habilidad asertiva para lograr un clima de paz y armonía, compromiso e identificación con la empresa.

4. La Organizaciones Aprendientes buscan que los trabajadores sean innovadores, tengan iniciativa y confianza en sí mismos; que participen y que tengan poder de decisión (Empowerment) y sobre todo sean asertivos en todo momento.

5. Es importante entender la naturaleza de la comunicación asertiva, ya que esta cualidad es la parte nuclear de toda organización empresarial. Por otro lado, hay que tener en cuneta su importancia para manejar con éxito las relaciones humanas y poder sobrevivir en un mundo totalmente globalizado. 
BIBLIOGRAFÍA

BOTTA, Mirta

1994. Comunicaciones Escritas en las Empresas. Editorial Granica, Argentina.

CASTENYER, Olga

1996. La Asertividad. Expresión de una Sana Autoestima. Editorial Desclee de Brower.

FISCHAN, David

2000. El Camino del Lider. Editorial ElComercio, Perú.

HOMS QUIROGA, Ricardo 1990. La Comunicación en la Empresa. Editorial Iberoamericana, México DF.

HARVARD DEUSTO

1999. Bussines Review.

Editorial Deusto Barcelona

MONTGOMERY URDAY, William

1999. La Asertividad, Autoestima y Solución de Conflictos. Editorial Círculo de Estudios Avanzados.

LEAVITT, Harold

1990. Psicología Gerencial. Editorial Contabilidad Moderna, Buenos Aires.

RODRÍGUEZ ESTRADA, Mauro 1991. Asertividad para negociar. Editorial Mc. Graw Hill. México. D.F.

RODRÍGUEZESTRADA, Mauro 1994. Comunicación y Supervisión Personal. Ed. Manual Moderno. México DF.

ROBINS, Stephen 1999. Comportamiento Organizacional. Ed. Prentince Hall
SCHEINCOHN, David

1995. Comunicación Estratégica: Management y Fundamentos de la Imagen Coorporativa. Ed. Addison Werley. Iberoamericana. Bogotá.

WILLMIINGTON, D.

1995. La Comunicación en las Organizaciones. Ed. Addison Werley. Iberoamericana. Bogotá. 